\title{
COVID-19 infection in symptomatic pregnant women at the midpoint of the pandemic in Spain: a retrospective analysis
}

\author{
Elias Ortiz ${ }^{1}$, RAFAEL HERNANDEZ PAILOS ${ }^{1}$, Maria Pola Guillen ${ }^{1}$, Ana Isabel Pascual \\ Pedreño ${ }^{1}$, Eduardo Rodriguez ${ }^{1}$, and Antonio Hernandez Martinez ${ }^{2}$ \\ ${ }^{1}$ Hospital la Mancha Centro \\ ${ }^{2}$ Universidad de Castilla-La Mancha - Campus de Ciudad Real
}

May 6, 2020

\begin{abstract}
Objective: Determine the strengths and weakness of a symptomatic screening for COVID-19 in pregnant women. Analyze the clinical presentation, management and outcomes. Design: Descriptive retrospective observational study. Setting: ManchaCentro Hospital (Spain) Population: Symptomatic pregnant women with confirmed diagnosis of COVID-19. Methods: Between the 12th of March and 17th of April 2020, all the symptomatic pregnancies were screened with diagnostic test for SARS-CoV2. Data collection was done by reviewing the medical records and telephone interviews. Main outcomes measures: Clinical characteristics, management, treatment, and obstetric and neonatal outcomes. Results: 20 patients with positive COVID-19 diagnostic test out of thirty-four suspected. The most common symptoms were fever $70 \%$, cough $65 \%$ and myalgia $35 \%$. A unique symptom of presentation in $20 \%$ of the cases. COVID-19 pneumonia was diagnosed in $30 \%$ by chest X-ray and one case had pulmonary embolism associated diagnosed by CT-Scan. Thromboprophylaxis was indicated in 16/20 patients. Eight women finished their pregnancy during the observation period. Type of birth: $25 \%$ natural birth, $12.5 \%$ assisted vaginal delivery and $62.5 \%$ caesarean section. We had three severe cases, two of them with intensive care support. All neonates had negative test for COVID 19 infection. Conclusions: We recommend universal screening of all pregnant woman for COVID-19 during the pandemic because of the limits of the symptomatic screening seen in this studio and the ratio of asymptomatic pregnancies with positive test for COVID-19 recently published. Funding: No funding. Keywords: COVID-19, pregnancy, screening, outcomes, symptoms, delivery.
\end{abstract}

\section{Hosted file}

MAIN TEXT with tables and figures. COVID-19 infection in symptomatic pregnant women at the midpoint of available at https://authorea.com/users/317927/articles/447979-covid-19-infection-insymptomatic-pregnant-women-at-the-midpoint-of-the-pandemic-in-spain-a-retrospectiveanalysis

\section{Hosted file}

Figures and tables. BJOG. .docx available at https://authorea.com/users/317927/articles/ 447979-covid-19-infection-in-symptomatic-pregnant-women-at-the-midpoint-of-the-pandemicin-spain-a-retrospective-analysis 